\title{
ballot
}

\section{Menos proibições e mais transparência: as (falsas) promessas sobre a vedação de doaçóes de pessoas jurídicas no financiamento de campanhas eleitorais ${ }^{1}$}

\author{
Ana Claudia Santano² (PUC/PR, Brasil) \\ anaclaudiasantano@yahoo.com.br \\ Rua Imaculada Conceição, 1155 - Bloco Vermelho \\ Prado Velho - Curitiba/PR CEP: 80215-901
}

1. Este trabalho é uma versão acrescentada de reflexões posteriores à publicação de SANTANO, A. C. A proibição das pessoas jurídicas em doar recursos econômicos para as campanhas eleitorais brasileiras: certo ou errado?. In: SANTANO, A. C.; SALGADO, E. D. Direito Eleitoral - debates ibero-americanos. Memórias do V Congresso Ibero-americano de Direito Eleitoral e do IV Congresso de Ciência Política e Direito Eleitoral do Piauí. Curitiba: Íthala, 2014. p. 363-382.

2. Pós-doutoranda em Direito Público Econômico pela Pontifícia Universidade Católica do Paraná - PUC/ PR; doutora e mestre em Ciências Jurídicas e Políticas pela Universidad de Salamanca, Espanha; professora de cursos de pós-graduação em instituições brasileiras e estrangeiras; membro da Asociación Iberoamericana de Derecho Electoral - AIDE; membro fundador da ABRADEP - Academia Brasileira de Direito Eleitoral e Político. 


\title{
Resumo
}

No atual debate da reforma política, um dos pontos centrais é o do financiamento de campanhas eleitorais é a proibição de doações de pessoas jurídicas. No afã de se responder prontamente aos mais recentes escândalos de corrupção, parece ser que o discurso veiculado desde o Congresso Nacional e seus interlocutores é que tal providência terá o condão de, pelo menos, diminuir a corrupção. Ocorre que não só não se acredita neste resultado, mas aqui se tentará demonstrar que haverá justamente o efeito reverso, o que será muito prejudicial ao sistema político brasileiro a longo prazo.

Palavras-chave: financiamento de campanhas eleitorais; democracia; corrupção; transparência.

\begin{abstract}
In the current debate on political reform in Brazil, one of the central points is the financing of election campaigns and the prohibition on corporate donations. In light of the most recent political corruption scandals, it might at first glance seem from the discourse emanating from the National Congress and lawmakers' interlocutors that efforts are under way that might at least reduce corruption. However, I argue that not only is this result unlikely, exactly the opposite might occur, which will be extremely harmful to the nation's political system in the long run.
\end{abstract}

Keywords: Campaign financing, democracy, corruption, transparency. 


\section{Um novo debate ou o retorno ao passado?}

Como já se tornou comum, o tema do financiamento de campanhas eleitorais volta a ser um dos pilares centrais dos debates da interminável reforma política em trâmite no Congresso Nacional. No entanto, se antes a preocupação era tão somente com o controle de gastos ou com o aumento do custo das campanhas, desta vez o financiamento vem conectado diretamente a grandes escândalos de corrupção, por meio de um discurso que induz ao entendimento de que, resolvendo-se o financiamento, revolver-se-á a corrupção na política brasileira.

Nada mais distante da realidade. Os novos tempos trazem ao centro do debate a relação dos partidos com o dinheiro, principalmente porque devido a sua dificuldade, os problemas da sua aceitação social são mais evidentes que no passado. Junto a isso, tanto nas eleiçóes quanto dentro dos próprios partidos não existem grandes incentivos para se adotar um comportamento racional econômico. O papel dos recursos econômicos na política é ambíguo e por isso que as reformas das leis que se relacionam ao tema não podem ser analisadas sem um diagnóstico do seu impacto e das possíveis mudanças que produzem no sistema democrático. ${ }^{3}$ Claro está que não há democracia sem partidos, e não pode haver partidos sem os recursos necessários para mantê-los, nem campanhas eleitorais eficazes sem recursos para produzi-las. ${ }^{4}$ Frente a isso, o primeiro problema que se expõe é a desigualdade econômica, que se contrapóe ao princípio da igualdade de oportunidades e que pode ameaçar a estabilidade do sistema. ${ }^{5} \mathrm{O}$ segundo problema é a dependência econômica dos partidos políticos e candidatos perante as fontes de financiamento mais vantajosas, sendo tudo isso acompanhado pelo encarecimento das campanhas eleitorais. ${ }^{6}$

Ou seja, é inegável que o dinheiro tem na política uma posição central. A expressão de Nassmacher de que o dinheiro é como o leite materno da política é muito pertinente para o momento que se está passando. Os cidadãos, quando não têm interesse ou mesmo talento para participar da política não parecem estar dispostos a conceder o seu tempo, fazendo com que o dinheiro seja uma opção recorrente de substituição destes canais, adaptando assim uma peculiar forma de participação social democrática. ${ }^{8}$ É nesta linha que a regulação do financiamento da política adquire importância ímpar como forma de tentar manter aos partidos pro-

3. Cf. MILYO, Jeffrey. "The Political Economics of Campaign Finance”. In: The Independent Review. v. III. no 4, [s.1.] 1999, p. 541-545.

4. NASSMACHER, Karl-Heinz. "Introduction: Political Parties, Funding and Democracy”. In: AUSTIN, R.; TJERNSTRÖM, M. (eds.): Funding of Political Parties and Election Campaigns. International IDEA, Stockholm, 2003.p. 4.

5. Cf. LANCHESTER, Fulco. "Introduzione: Il Finanziamento della Politica tra forma de Stato e Vincoli Sistemici". In: LANCHESTER, F. (a cura de): Finanziamento della Politica e Corruzione. Giuffrè, Milano, 2000. p. 7-10.

6. BURNELL, Peter. “Introduction", In: BURNELL, P., WARE, A. (eds.): Funding Democratization, Manchester University Press, UK, 1998. p. 6.

7. Cf. NASSMACHER, Karl-Heinz. "Comparative Political Finance in Established Democracies". In: NASSMACHER, K-H. (ed.): Foundations for Democracy - Approaches to Comparative Political Finance. ed. Nomos Verlagsgesellschaft, Baden-Baden, 2001, p. 9.

8. ALEXANDER, Herbert E. "Money and Politics: Rethinking a Conceptual Framework”. In: ALEXANDER, H. E. (ed.): Comparative Political Finance in the 1980's. Cambridge University Press, UK, 1989. p. 10. 
tegidos das pressões econômicas e também de garantir o princípio da igualdade de oportunidades dentro da esfera eleitoral ${ }^{9}$, fazendo com que os sistemas de financiamento tenham que decidir a justa medida entre o financiamento público e privado. ${ }^{10} \mathrm{Tem}$-se que o nível ideal de financiamento dos partidos políticos deveria ser aquele que os fizesse capazes de estabelecer conexões próprias com todos os votantes, sem fazer com que a arrecadação de recursos fosse o seu fim último ou que a sua atuação resulte condicionada pelos seus financiadores. $\mathrm{O}$ ideal seria que os partidos políticos arrecadassem fundos desde amplas faixas sociais, refletindo a plural estrutura de interesses existente. ${ }^{11}$

Neste sentido, o que se debaterá neste artigo é se a atual medida de proibição das doações realizadas por pessoas jurídicas é realmente pertinente e benéfica para o sistema político brasileiro. As expectativas depositadas sobre esta decisão são muitas e vão desde um maior equilíbrio de forças econômicas nas campanhas, até a diminuição de casos de corrupção. Teme-se que a discussão está sendo bastante simplista frente a um problema tão complexo, e que ignorar diversos elementos que não estão sendo devidamente abordados pode acarretar em graves consequências a longo prazo. Somente cabe lembrar que este debate já foi realizado em outro momento político importante que foi nas eleições de Fernando Collor de Mello e o seu impeachment. E o resultado foi pela permissão das pessoas jurídicas em realizar doaçóes, já que era uma realidade inconteste.

\section{2. É só o voto que vale? As diversas formas de participação política na democracia moderna}

As ciências sociais se ocuparam diretamente na formulação de uma tipologia que pudesse catalogar as diversas formas de participação política, e na impossibilidade de se elencar a todas - devido aos limites deste trabalho - mencionam-se algumas, como persuadir os outros a votar; trabalhar ativamente para partidos ou candidatos; participar das reuniões políticas ou comícios; contribuir com recursos econômicos a partidos e candidatos; ser membro de algum clube político; participar ativamente em organizações comunitárias para a resolução de problemas, manter contato com lideranças locais ou nacionais, seja socialmente ou de forma personalizada; dentre outras. ${ }^{12}$ Essa lista de atividades que se configuram como participação política permite visualizar que, em algumas delas, é necessário tempo, em outras, habilidades, e em outras, dinheiro. ${ }^{13}$ Praticamente todas têm um alcance coletivo dos seus resultados e são fruto de uma participação ativa, indo muito mais além do conceito extremamente restrito de

9. GIL CASTELLANO, José. “La Financiación de los Partidos Políticos: El Estado de la Cuestión”. In: Cuadernos Constitucionales de la Cátedra Fadrique Furió Ceriol, n³6/37, Valencia, 2001, p. 249.

10. GONZÁLEZ-VARAS, Santiago: La Financiación de los Partidos Politicos. Dykinson, Madrid, 1995. p. 22

11. WARE, Alan. "Conclusions". In: BURNELL, P., WARE, A. (eds.): Funding Democratization, Manchester University Press, UK, 1998. Pp. 230-232; NASSMACHER, K-H."Introduction...” p. 9-13.

12. Classificação constante em VERBA, Sidney; NIE, Norman H. "Participation in America - Political Democracy and Social Equality. Harper \& Row Publishers: New York, 1972. p. 72.

13. VERBA, Sidney; NIE, Norman. H.; KIM, Jae On. "The modes of democratic participation: a crossnational comparison". Sage: Beverly Hills, California, 1971.p. 55 e ss. 
participação política somente pela emissão do voto, deixando claro que o tempo e as habilidades requeridas por parte dessas formas de participação política podem ser substituídos por recursos econômicos ${ }^{14}$, sem que se interfira no funcionamento da democracia. Dinheiro, como elemento de participação política, é tão natural quanto o próprio direito de votar, além de ser uma evidência do envolvimento da sociedade na arena política, o que é bastante saudável.

Tal concepção limitativa da participação política ao exercício do voto pode ser resultado da confusão dessa idéia com os efeitos da apatia por parte dos cidadãos frente ao sistema político ${ }^{15}$ Há notoriamente um aumento na abstenção eleitoral, resultante de certa desilusão com a política ${ }^{16}$, e também um aumento no número de protestos, de formas alternativas de participação política que vai além da ação isolada do cidadão, desembocando em uma ação verdadeiramente coletiva, promovida por grupos sociais, sejam estes formais ou informais. ${ }^{17}$ O fato que é o conceito de participação política atualmente extrapola o seu perfil jurídico de direito fundamental individual expresso por meio do voto e passa a ser visto amplamente na esfera coletiva. Os cidadãos se organizam em grupos ou organizações motivados por interesses em comum, como forma de fortalecer o alcance das suas demandas e superar a fraqueza da influência individual de cada um deles. Eleger a maneira de como será realizada essa participação política também é uma resultante da própria participação política, não sendo permitido que isso esteja limitado tão somente ao agir individual e unitário. ${ }^{18}$

Se for assim, pode-se contestar a idéia individualista de participação política e conceder tal direito também às pessoas jurídicas, que podem não votar, mas que exercem um forte protagonismo na política como um todo e que também são afetadas pelas decisões tomadas pelo Estado. Tais entes privados de modo algum se limitam a empresas ou sociedades com ânimo de lucro ${ }^{19}$, e não podem ser sumariamente excluídos da arena pública, como se pretende com o atual discurso da reforma política. Tal protagonismo das pessoas jurídicas não pode ser associado a uma narrativa negativa da sua relação com a política e a sua mobilização é sinal de saúde do sistema democrático como um todo, afinal, elas também são agentes ativos da sociedade, possuem demandas a serem atendidas pelo Estado, bem como se organizam em prol de suas causas. Natural que queiram participar por completo da democracia.

14. VERBA, Sidney, SCHLOZMAN, Kay Lehman; BRADY, Henry E."Voice and equality. Civic voluntarism in American politics". Cambridge, Mass.: Harvard University Press, 1995. p. 48.

15. CUNHA, Camila Santos da; EPPLE, Cristiane; HERATH, Maikiely. O direito fundamental de participação social no estado democrático de direito. Disponível em $<<$ http://www.conpedi.org.br/manaus/ arquivos/anais/brasilia/04_365.pdf >> Acesso em 03.04.2014.p. 986.

16. Ainda que a abstenção eleitoral se explique por diversos fatores, é fato que nas eleições gerais de 2014 houve um recorde na taxa de não comparecimento, chegando a 30.137.479 de eleitores. Considerando que no Brasil o voto é obrigatório, não é de se ignorar tal percentual. (fonte: www.tse.jus.br).

17. BRITO, Walderes Lima de. Superação da apatia política pela valorização de novas práticas de participação cidadã. Disponível em <<http://www.pucgoias.edu.br/ucg/ser/ArquivosUpload/1/file/Artigos/pdf/superacao_apatia.pdf $>>$ Acesso em 03.04.2014.

18. DALLARI, Dalmo de Abreu. O que é participação Política?. São Paulo: Brasiliense, 1999. Coleção primeiros passos. p. 85 e ss.

19. Segundo o art. 44 do referido Código, são tidas como pessoas jurídicas de direito privado no Brasil as associações; as sociedades; as fundações; as organizações religiosas; os partidos políticos; e as empresas individuais de responsabilidade limitada. 
Segundo o próprio conteúdo do Código Civil vigente, tem-se que as pessoas jurídicas se caracterizam por sua capacidade de fato e de direito; pela existência de uma estrutura organizativa artificial; pelos objetivos comuns de seus membros; por um patrimônio próprio e independente do de seus membros; bem como pela publicidade da sua constituição ${ }^{20}$ Desprende-se dos artigos 45 e seguintes que o ordenamento brasileiro optou pela teoria da realidade técnica das pessoas jurídicas ${ }^{21}$, ou seja, que elas são o resultado de um processo técnico - a personificação - através do qual se atribui personalidade a grupos e organizações que a norma reconhece vontade e fins próprios. Ainda que sejam produtos da ordem jurídica, não se trata de uma ficção, mas sim de uma realidade, da tradução jurídica de um fato, cabendo ao direito tão somente o seu reconhecimento. ${ }^{22}$ No entanto, seja qual for o fundamento jurídico ou a base teórica, tanto nas pessoas físicas quanto nas jurídicas há dois elementos, o natural e o jurídico. Assim sendo, a noção de pessoa jurídica é bastante similar a de um sujeito de direito, na qual a idéia que embasa a pessoa física e a jurídica são análogas. A pessoa jurídica existe no plano real e no mundo das relações jurídicas, sendo, portanto, uma realidade inegável que forma um novo ponto central de direitos e deveres. ${ }^{23} \mathrm{O}$ conceito de pessoa física é, do mesmo modo que o de pessoa jurídica, uma construção também jurídica, o que não permite diferenças entre um e outro. Ambos são tratados como uma unidade pelo Direito, até pelo fato de que a pessoa jurídica se move de acordo com as ações dos homens que a compõem. ${ }^{24}$

Sonegar o direito de participação política das pessoas jurídicas é também sonegar parte desse direito dos indivíduos que as constituem, negando-lhes a prerrogativa de autoorganização e mobilização na sociedade. É aqui que reside o núcleo central da discussão sobre adequação da proibição ou não das pessoas jurídicas em realizar doações para partidos e campanhas eleitorais.

\section{Doações privadas para campanhas eleitoraisł uma realidade inafastável}

A natureza jurídica de direito privado dos partidos político determina que eles próprios devam obter os seus ingressos a partir das fontes que mais lhes forem convenientes. ${ }^{25}$ Porém, isto ocorre em um contexto de escassez de fontes de arrecadação, campanhas eleitorais cada vez

\footnotetext{
20. AMARAL, Francisco. “Direito Civil - Introdução”. $3^{\circ}$ ed., Rio de Janeiro: Renovar, 2000. p. 272.

21. Não serão expostas aqui as críticas formuladas contra essa teoria. Para tanto, Cf. LEONARDO, Rodrigo Xavier. Revisitando a teoria da pessoa jurídica na obra de J. Lamartine Corrêa de Oliveira. Disponível em $<<$ http://ojs.c3sl.ufpr.br/ojs/index.php/direito/article/view/14977>> Acesso em 03.04.2014.p. 126 e ss.

22. RONCERO, Francisco Capilla: "La persona jurídica - funciones y disfunciones". Madrid: Tecnos, 1984. p. 52 .

23. AMARAL, Francisco. Op. Cit. p. 281.

24. KELSEN, Hans: Teoria Geral do Direito e do Estado. São Paulo: Martins Fontes, 1995. p. 100.

25. MARTÍNEZ SOSPEDRA, Manuel: Introducción a los Partidos Políticos. Ariel, Barcelona, 1996. p. 64.
} 
mais caras e uma opinião pública muito avessa a tais organizaçóes partidárias e com a classe política como um todo. ${ }^{26}$

A regulação do financiamento privado dos partidos políticos não atende à imparcialidade, não é neutra e não garante a igualdade de oportunidades entre tais agremiações em muitos países, uma vez que é resultado direto da sua prerrogativa de autorregulação. Uma normativa absolutamente permissiva do tema em tópicos como as doações iria favorecer aos setores economicamente mais fortes da sociedade, alterando a ideia de igualdade. ${ }^{27}$ Por outro lado, considera-se também que o financiamento privado pode ser mais eficaz contra a corrupção quando acompanhado de fortes medidas de transparência e publicidade, já que obriga aos partidos políticos a cuidar da sua credibilidade frente ao eleitorado e a realizar uma melhor gestão dos recursos. Evidentemente, também é uma forma de participação política, já que ao mesmo tempo fomenta a relação de confiança entre os partidos e os cidadãos, estimulando o trabalho das organizações locais dos partidos na captação desses recursos. Em resumo: o modelo privado de financiamento é, definitivamente, o que corresponde à natureza predominantemente jurídico-privada dessas organizaçóes no ordenamento de grande parte dos países de democracia ocidental ${ }^{28}$, como o brasileiro.

Não é possível pensar que, na democracia atual, possam existir partidos alheios à atuação dos grupos de pressão, nem que as doações privadas a favor dos partidos não se constituam instrumentos importantes e não descartáveis de participação política voluntária. ${ }^{29}$ Contudo, a direta e automática associação entre grupos de pressão, doações privadas e corrupção em nada se assemelha à realidade. A atuação dos grupos de pressão geralmente é realizada por meio de lobbies, um termo que também é muito estigmatizado por causa da corrupção. Por mais que existam áreas "cinzentas" entre eles, como ocorre com o financiamento de campanhas eleitorais, lobby não é corrupção, nem grupo de pressão. $\mathrm{O}$ lobby defende interesses de agentes identificáveis por meio de um processo que, em princípio, exclui totalmente a troca de favores, como também o faz o financiamento de campanhas eleitorais. Além disso, o lobby exclui mutuamente a corrupção, pois fazer lobby é dispendioso, caro, não tendo um resultado certo, algo que é descartado com a corrupção, que costuma ser imediata e pode ser inclusive mais barata. ${ }^{30}$ Doações privadas que são usadas para corrupção seguem o mesmo raciocínio: é insegura no que tange à obtenção de favores, pode ser muito cara se comparada a atos de

26. ALBERTO CORDERO, Luís."La Fiscalización del Financiamiento de los Partidos Políticos: un Asunto de Conciencia Crítica". In: AA.VV.: Administración y Financiamiento de las Elecciones en el Umbral del Siglo XXI - Memoria del III Congreso Internacional de Derecho Electoral. Tomo II, Instituto de Investigaciones Jurídicas, DF, México, 1999. p. 381-382.

27. FERREIRA RUBIO, Delia. "Financiamento de Partidos e Campanhas: Fundos Públicos versus Fundos Privados". In: Novos Estudos, n 73, nov, ed. CEBRAP, 2005. p. 10-11.

28. CASTILLO, Pilar. del."Objetivos para una Reforma de la Legislación sobre Financiación de los Partidos Políticos". In: La Financiación de los Partidos Políticos. Cuadernos y Debates, n 47, Centro de Estudios Constitucionales, Madrid, 1994. p. 61-63.

29. Cf. MOLINA VEGA, José Enrique; SADEK, María Tereza. “Participación Política”. In: AA.VV.: Diccionario Electoral. CAPEL-IIDH, Costa Rica, 1989. p. 513. Além disso, Cf. LUCIANI, Massimo."Danaro, Política e Diritto". In: Rivista di Diritto Costituzionale. Ed. G.Giappichelli, Torino, 2006. p. 7.

30. GRAZIANO, L. O lobby e o interesse público. Revista Brasileira de Ciências Sociais. v. 12, no 35, fev., 1997. Disponível em: <<http://www.scielo,br/scielo.php?script=sci_arttext\&pid $=$ S0102-69091997000300009 > > Acesso em 20.08.2014. 
corrupção mais diretos, e uma vez que se doe para fins pouco éticos, provavelmente os envolvidos se verão aprisionados a este pragmatismo nefasto, já que não há valores suficientes para a política, nem para o poder.

As vantagens e desvantagens que as doações proporcionam vão desde a possibilidade de solução rápida dos problemas econômicos das agremiações partidárias, até o inconveniente de ser uma arma para exercer influência na agenda política ou uma possível dependência dos partidos frente a estes grandes doadores, vendo-se "obrigados" (dentro da dinâmica da troca de favores) a lhes conceder algum tipo de privilégio nos programas do partido, ou inclusive do governo, quando o partido que recebeu doações aceda às quotas do poder. ${ }^{31}$ Justamente é a possível dependência dos partidos, bem como a influência desmedida dos doadores, que torna essa fonte de financiamento tão polêmica, e é o que a converte em objeto de uma maior regulação por meio de limites máximos, proibições, etc.

Entretanto, frise-se: não é factível querer afastar os partidos dos recursos alheios. ${ }^{32} \mathrm{O}$ dinheiro procedente de doações privadas sempre estará presente nas arcas dessas organizações, e quanto mais proibitivas ou restritivas sejam as normas, provavelmente serão mais ineficazes. Exemplo disso são as normas limitativas dos Estados Unidos na época do escândalo "Watergate", bem como no sistema espanhol, que embora muito rígido em relação às doações privadas, como não conta com um mecanismo forte de fiscalização, tais normas tornam-se pouco ou nada efetivas.

Quando se fala de doaçóes aqui não se refere prioritariamente aos cidadãos doando seus recursos econômicos a favor de uma opção política, mas a empresas, pessoas jurídicas que têm um evidente potencial para colaborar com os partidos e para a realização de suas campanhas. Ainda que não se destaque que existam cidadãos que realizem doações por altruísmo, não se ignora o fato de que é mais comum encontrar a importantes empresas detrás de avultadas doações, e aqui é que reside a maior quantidade de casos de corrupção. Os grandes escândalos envolvendo o financiamento de partidos e doações de empresas têm um longo histórico sem respeitar fronteiras. É aqui que reside grande parte da fundamentação dos que defendem a proibição total de doações realizadas por empresas. ${ }^{33}$

É verdade que as doaçóes deveriam ter mais um perfil de ajuda. Contudo, a ideia procedente dos partidos de quadros de que as doaçóes deveriam ser significativas e constantes faz com que se produza uma desigualdade considerável entre as formações como um todo. ${ }^{34}$ Por

\section{GARCÍA COTARELO, Ramón: Los Partidos Políticos. ed. Sistema, Madrid, 1985. p. 198.}

32. ZOVATTO afirma que a relação entre o dinheiro e a política é vital para a saúde e a qualidade da democracia, porque é uma ferramenta importante de fazer política. Contudo, na América Latina, o tema do financiamento político está muito relacionado com a desilusão que se tem com a própria política, pois os escândalos de corrupção, tráfico de influência, dentre outros, estão muito presentes na opinião pública, e tanto partidos como candidatos se acusam mutuamente de conseguir capital de origem duvidosa ou de utilizar dinheiro de maneira inapropriada. (In: ZOVATTO, Daniel; FREIDENBERG, Flavia."Democratización Interna y Financiamiento de los Partidos Políticos”. In: PAYNE, M.; et al (eds.): La Política Importa: Democracia y Desarrollo en América Latina. BID e Instituto Internacional para la Democracia y la Asistencia Electoral, Washington D.C., 2006. p. 214-215).

33. Nesse sentido, Cf. SATRUSTEGUI GIL DELGADO, Miguel. "La Reforma Legal de los Partidos Políticos”. In: Revista Española de Derecho Constitucional. año 16, n 46, ene/abr, 1996. p. 101.

34. MARTÍNEZ SOSPEDRA, Manuel. "La Financiación de los Partidos Políticos. Ensayo de Aproximación". In: Cuadernos Constitucionales de la Cátedra Fadrique Furió Ceriol, n 11/12, Valencia, $2^{\circ}$ época, 1995. p. 20-21. 
outro lado, cabe sublinhar que, dependendo da posição do partido dentro do espectro político, ele será mais favorecido ou não pelas doações privadas, já que a posição ideológica do partido não resulta uma variável independente do nível sócio-econômico de seus potenciais eleitores, gerando uma desigualdade que pode afetar o equilíbrio de condições na contenda eleitoral. ${ }^{35}$

Os problemas que se conectam com a questão das doações privadas vão muito mais além do fluxo de recursos econômicos entre indivíduos ou empresas e partidos. $\mathrm{O}$ direito à liberdade de expressão é invocado muitas vezes nesse ponto, porque tanto os cidadãos de maneira individual, quanto através de uma corporação, têm o direito de declarar a sua simpatia por uma opção política, bem como a de colaborar economicamente com ela. $\mathrm{O}$ conflito existente entre a transparência e o controle das finanças partidárias e o direito à liberdade de expressão ressurge muito frequentemente em países como os Estados Unidos, por exemplo. E como naquele país a liberdade de expressão integra decisivamente o conteúdo da First Amendment da Constituição estadunidense, a questão tende a ser ainda mais polêmica. Há outros debates sobre o controle das finanças dos partidos e a publicidade de seus dados, o que entra, por sua vez, pode entrar em conflito com o segredo do voto ou com o eventual direito ao anonimato.

\section{E o que pode acontecer no Brasil? Os efeitos da proibição de pessoas jurídicas de realizar doaçóes para os partidos e campanhas eleitorais}

O debate sobre a possibilidade das pessoas jurídicas em participar do processo eleitoral por meio de recursos econômicos foi fomentado pelo julgamento perante o Supremo Tribunal Federal da Ação Direta de Inconstitucionalidade 4.650 promovida pelo Conselho Federal da Ordem dos Advogados do Brasil, paralelamente às discussóes que acompanham a eterna reforma política. Com o atual discurso meramente moralizador da política, o resultado já podia ser previsto com certa antecedência, o do provimento da ação ${ }^{36}$ Porém, isso provocou um vazio legislativo e uma profunda mudança no sistema de financiamento da política no Brasil, sem que se visualize um novo modelo a curto e médio prazo.

Contudo, não se aborda com atenção o que poderá ocorrer com esta decisão.

Em primeiro lugar, é importante frisar que, segundo dados do Instituto IDEA, de 170 países constantes do seu banco de dados, somente 38 proíbem doaçóes de pessoas jurídicas especificamente empresas - para o financiamento da política. ${ }^{37} \mathrm{Com}$ a decisão do STF, o Brasil se soma a um grupo ainda mais minoritário, que entende que qualquer pessoa jurídica, inde-

35. Compartilha essa posição ZOVATTO, que entende que pode haver dois tipos de doações: aquelas que o doador faz porque quer realmente participar na política e apoiar o seu partido de preferência, e aquelas em que o doador está interessado em adquirir influência política ou comprar acesso a qualquer dos privilégios que a política pode oferecer. (In: ZOVATTO, Daniel: Dinero y Política en América Latina: Una Visión Comparada. International IDEA, Lima, 2003.p. 43).

36. No momento de elaboração desse artigo, 5 ministros já haviam votado pela procedência da ação, outro pela procedência parcial, havendo somente um voto divergente. Dessa forma, o resultado da ADI já está determinado, mesmo que o julgamento ainda não tenha sido concluído.

37. Dado disponível em <<http://www.idea.int/political-finance/question.cfm?field=248\&region=-1 >> Acesso em 05.04.2014. 
pendentemente de qual seja, não deve participar de forma alguma do processo político. Aliado a isso, também é relevante se ter em mente que na legislação brasileira já existem escassas fontes de arrecadação de recursos por parte de partidos e candidatos, limitando-se a quatro: doações privadas (agora limitadas às pessoas físicas); recursos do fundo partidário; recursos do partido; e recursos próprios. Há, claramente, uma penalização dos canais de obtenção de recursos, resultado direto da desconfiança que normalmente pauta a relação da política com o dinheiro e a existência de casos de corrupção.

Logo, também se faz presente na lei brasileira a tendência latinoamericana de vedação de fontes de arrecadação, que engloba 11 entes: governos e entidades estrangeiras; órgãos da Administração Pública direta e indireta; concessionários de serviços públicos; entres de direito privado que recebem contribuiçóes compulsórias por lei; entidades de utilidade pública; pessoas jurídicas sem fins lucrativos que recebam recursos do exterior; entidades beneficentes e religiosas; entidades esportivas que recebem recursos públicos; organizações não governamentais que recebem recursos públicos; organizações da sociedade civil de interesse público; e entidades de classe e sindicatos. Se comparados com as fontes permitidas, nota-se a forte restrição dos canais de arrecadação em vigor, o que, por si só, coloca os partidos e candidatos em uma delicada situação: eleger seguir a lei e arriscar-se a não ter êxito nas urnas, ou recorrer ao financiamento irregular, para ter alguma chance de vitória, dentro de um contexto onde as eleiçóes são altamente competitivas, relevando possíveis sanções.

Por outro lado, não é possível ignorar o comportamento das empresas no atual sistema de financiamento. Nas eleiçóes de 2010, as maiores doadoras de recursos para comitês e diretórios, tanto nas eleições proporcionais quanto majoritárias correspondem a duas construtoras, sendo a primeira a Construtora Andrade Gutierrez, com uma doação total de R $\$$ 64.620.000,00 nos estados de Minas Gerais e São Paulo; e a segunda a Construtora Queiroz Galvão, com doação total de R \$ 61.091.020,50 nos estados do Rio de Janeiro, Paraíba, São Paulo, Paraná, Pernambuco e Rio Grande do Sul. Independentemente da legalidade de tais valores - uma vez que constam no sistema do Tribunal Superior Eleitoral - nota-se que ambas as construtoras não doaram recursos para expressar a sua preferência eleitoral, mas sim o de ter influência no poder de qualquer opção política que vencesse as eleições. No caso da Andrade Gutierrez, as doações foram dirigidas ao PSDB, ao DEM e ao PT, e no caso da Queiroz Galvão, foram para o PMDB, PSB, PT, PP, PDT, PSDB e o DEM. Há, indubitavelmente, um comportamento bastante reprovável por parte das empresas dentro do sistema de financiamento ${ }^{38}$ e que permite observar que as grandes doações vêm de empresas muito pontuais, não alcançando a todas as opções políticas, mas tão somente aquelas que têm alguma chance de vitória nas urnas. ${ }^{39}$

Junto com isso, tem-se que o custo de uma campanha eleitoral no Brasil também é algo desproporcional. Ainda que com dados desatualizados, David Samuels já indicava que as eleições no Brasil custavam tanto quanto nos Estados Unidos, mesmo considerando o horário eleitoral gratuito. Segundo ele, as eleições brasileiras de 1994 tiveram um custo variando entre

38. Dados disponíveis no site do TSE (www.tse.jus.br) e Às Claras, da Transparência Internacional (www. asclaras.org.br).

39. Entende-se aqui que o argumento de que os partidos localizados na esquerda do espectro político não recebem grandes doações já não é mais totalmente válido. Ainda que historicamente os partidos esquerdistas sempre receberam menos doaçóes, o fato é que o PT, ainda que tenha passado por um processo de centralização de ideologia, por estar no poder detém uma parte bastante expressiva das doações de empresas. 
US\$ 3,5 bilhóes e US\$ 4,5 bilhóes, sendo que as estadunidenses de 1996 custaram cerca de US\$ 3 bilhões. ${ }^{40} \mathrm{O}$ TSE estima que os gastos da campanha eleitoral de 2006 somam aproximadamente R \$ 1,5 bilhão de reais. Só os candidatos, Luiz Inácio Lula da Silva (PT) e Geraldo Alckmin (PSDB), declararam gastos respectivos de $\mathrm{R} \$ 104,3$ milhóes e $\mathrm{R} \$ 81,9$ milhóes ${ }^{41}$. A evolução das doações declaradas, em 2002, chegou a $\mathrm{R} \$ 798.883 .813$, e em 2012 saltou para $R$ \$ 4.559.577.270. Uma diferença de 5,7 vezes a mais. ${ }^{42}$ Se houve aumento nas doaçóes, significa dizer que houve um aumento nos gastos de campanha, uma vez que, se um candidato gasta um valor alto, seu adversário não pensará duas vezes antes de gastar mais para superá-lo. ${ }^{43}$

Ao considerar o valor de todas as doaçôes de 2012 no ranking nacional, somente na posição $11^{\circ}$ é que figura uma pessoa física, que foi capaz de acompanhar os altos valores que constam dos big donors: Jorge Alberto Vieira Studart Gomes é empresário e político pelo PSDB, membro do Centro Industrial do Ceará, doador de $\mathrm{R} \$ 2.140 .000,00$. A próxima pessoa física aparece na $23^{\circ}$ posição da lista: Guerino Ferrarin, conhecido empresário do ramo da agricultura e pecuária do Grupo Ferrarin, doador de $\mathrm{R} \$ 1.246 .120,00 .{ }^{44}$ Do total de doações realizadas em 2010 e 2012, cerca de 11\% e 22,6\%, respectivamente, correspondem a doaçóes de pessoas físicas, sendo quase todas praticamente referente ao autofinanciamento. ${ }^{45}$

Com a proibição das pessoas jurídicas de realizar doaçóes para partidos e candidatos, dois efeitos podem ser causados de imediato: o primeiro é, sem dúvida, da interrupção abrupta dessa grande transferência de recursos para os partidos, deixando-os em uma situação bastante delicada para arcar com seus compromissos, seu sustento e suas campanhas. Sem ter como afrontar tais custos, com a escassez de recursos e com a ausência de medidas objetivas em prol da diminuição do custo da vida política, os partidos não titubearão antes de recorrer às vias irregulares de financiamento. Isso porque a proibição de pessoas jurídicas não está sendo acompanhada por medidas de fomento de doações de pessoas físicas ${ }^{46}$ - como poderia ser $\mathrm{o}$

40. SAMUELS, David. "Money, elections and democracy in Brazil". In: Latin America Politics and Society. v. 43, n. 2, 2001. p. 30 e ss; SAMUELS, David: "Ambition, federalism and legislative politics in Brazil", UK: Cambridge University Press, 2003. p. 25 e ss. Mais dados referentes às eleições de 1998 e 2002 podem ser encontrados em: SAMUELS, David. "Financiamento de campanhas no Brasil e propostas de reforma". In: SOARES, Gláucio Ary D.; RENNÓ, Lúcio R. (orgs.): Reforma Política - Lições da Historia Recente. Rio de Janeiro, FGV, 2006. p. 135.

41. www.tse.jus.br. Dados constantes na prestação de contas.

42. www.asclaras.org.br. Acesso em 07.04.2014.

43. Nas eleições proporcionais, o pensamento lógico de um candidato pode ser explicado da seguinte forma: se ele arrecadar mais, pode não ser eleito, mas se ele arrecadar menos que o mínimo para aquele estado ou município, ele seguramente não se elegerá. O valor mínimo varia de estado a estado, sendo que, nas eleições de 2010, o mínimo menor para uma campanha a deputado federal foi no estado do Ceará ( $R \$ 48.221,00)$, e o mínimo maior foi no estado do Mato Grosso ( $\mathrm{R} \$ 616.972,00)$. Receitas menores que esses limites se traduziam na derrota do candidato nas urnas. (http://www.excelencias.org.br/docs/custo_do_voto.pdf.p.6-7).

44. www.asclaras.org.br. Acesso em 07.04.2014.

45. http://www.excelencias.org.br/docs/custo_do_voto.pdf.p. 4.

46. Em 2010 e 2012, cerca de $92 \%$ dos recursos de pessoas físicas correspondiam à doações iguais ou superiores a $\mathrm{R} \$ 1.000,00$, que são geralmente de empresários que não desejam que as suas empresas apareçam nas listas de doadores, parentes de candidatos, etc. As doaçóes de pequeno valor (menos de R\$100,00) representam tão somente a $0,3 \%$ do financiamento eleitoral, deixando claro o afastamento do cidadão para com a política. (http://www.excelencias.org.br/docs/custo_do_voto.pdf. p. 4). 
abatimento fiscal de valores -, nem de medidas de fiscalização, comprometendo diretamente a transparência e formando um ambiente muito propício para o denominado "caixa 2", ou o financiamento não declarado ${ }^{47}$. Como efeito mediato, aumentará ainda mais a percepção e a ocorrência de corrupção política, o que agrava ainda mais o descrédito e a repulsa pela classe política. Sublinha-se que o que se está proibindo são as doações lícitas e registradas de pessoas jurídicas, sem nenhuma providência contra as ilícitas e não declaradas.

Contudo, deve-se lembrar que tal proibição não atinge somente às empresas, mas também a qualquer pessoa jurídica, não fazendo sequer a diferenciação entre uma empresa $\mathrm{e}$ uma associação sem fins lucrativos em favor de alguma demanda. Isso tolhe diretamente o direito de participação política daquelas organizações que legitimamente buscam influir na política, pleiteando causas que expressam um determinado grupo social. Não se cogitou na possibilidade de especificar quais seriam as pessoas jurídicas proibidas de realizar doações, generalizando a todas sem respeitar suas diferenças ou o seu real poder de influência. $\mathrm{O}$ alvo eram as grandes empresas. Porém, não existiu a preocupação em se detalhar isso e acabou-se incluindo todas, o que certamente será percebido a longo prazo, uma vez que afasta os cidadãos da vida pública, mais ainda do que paulatinamente já vêm sendo afastados.

Outra conseqüência frente à falta de fontes de arrecadação será o aumento gradativo do financiamento público de partidos e campanhas como a única solução possível para manter os partidos ativos. Ignora-se o risco de trocar uma dependência por outra, ou seja, que os partidos deixem de depender dos recursos econômicos das empresas, e passem a depender dos recursos públicos para a sua sobrevivência, causando uma lenta e constante estatização das agremiações partidárias. Não se debate esse risco quando se explicam os "benefícios" do financiamento público, mas ele é muito presente e bastante evidente em países como a Espanha, que conta com níveis altíssimos de financiamento público - beirando os $90 \%$-, provocando uma estrita subordinação dos partidos aos recursos públicos, bem como uma petrificação preocupante no sistema de partidos. ${ }^{48}$

A proibição de doações vindas desde as pessoas jurídicas, por si só, pouco ou nada colaborará para a situação atual do financiamento político no Brasil. Sistemas extremamente proibitivos têm grande probabilidade de serem ineficazes, tendo isso ocorrido em países com democracia robusta, como os Estados Unidos. É ingênuo pensar que tão só pela proibição de doações licitamente realizadas, tais recursos não chegarão aos cofres dos partidos e candidatos. Olvidou-se que dinheiro é um elemento deveras complicado de conter, sendo como a água: fecha-se um canal, abrem-se à força outros dez.

47. Concorda-se com a opinião expressa por Claudio Weber Abramo, da Transparência Brasil. http://www. excelencias.org.br/docs/custo_do_voto.pdf. p. 12.

48. Para uma análise detalhada do sistema espanhol, Cf. PAJARES MONTOLIO, Emilio: La Financiación de las Elecciones. Congreso de los Diputados, Madrid, 1998. p. 33 e ss; CORTÉS BURETA, Pilar: Recursos Públicos y Partidos Politicos: Balances y Perspectivas de Reforma. Centro de Estudios Políticos y Constitucionales, Madrid, 2003. p. 160 e ss. 


\section{Os nós górdios da legislação sobre financiamento de campanhas}

Escândalos políticos provocam reformas que, ao final, resultam pontuais e pouco eficazes para o alcance dos objetivos de antes. O Brasil não é exceção disso. Deve-se admitir que as últimas soluções implementadas pecam com frequência por uma excessiva generalidade ${ }^{49}$, e de uma falta de coerência sistemática ${ }^{50}$ fruto, em muitas ocasióes, de múltiplas intervenções por parte do Poder Judiciário. Nesse marco, as modificações na legislação eleitoral brasileira são constantes e os partidos, sob o pretexto de dar uma solução ao problema em concreto, tendem a fechar o sistema para maximizar as vantagens disponíveis do que de fomentar a igualdade de oportunidades para o acesso às funções públicas, ou de proteger a livre formação de opinião dos eleitores. ${ }^{51}$ Essa tendência se observa não só na normativa referente ao financiamento, mas também no registro de partidos e na propaganda eleitoral.

No entanto, não se foca diretamente nos reais problemas do sistema de financiamento. Sem mudanças profundas e repentinas no sistema e com apenas alguns ajustes, os custos de uma reforma na lei seriam bastante menores e atenderiam muito mais aos preceitos da democracia.

Um dos pontos neurálgicos é, sem dúvida, a ausência de um limite nominal nas doações de pessoas físicas e jurídicas. No que tange às pessoas físicas, normalmente os que realizam doações são grandes empresários ou políticos que se autofinanciam ${ }^{52}$, com considerável patrimônio declarado e com real poder de influência no processo eleitoral. O limite máximo de $10 \%$ para as doações de pessoas físicas favorecem sobremaneira a estas expressivas doações de pessoas abastadas, afastando os cidadãos de situação econômica mais corriqueira a participar da política por este canal pela crença de que simplesmente será uma "perda de tempo" realizar uma campanha sem recursos para tal. E eles têm razão em pensar assim. A cada processo eleitoral nota-se um importante decréscimo no número de pessoas físicas com rendimentos regulares ou mais modestos, abrindo-se ainda mais espaço para as pessoas de classes mais favorecidas.

É o mesmo que ocorre com as empresas, também beneficiadas por um limite de $2 \%$ sobre o faturamento bruto obtido no ano anterior. Claro está que $2 \%$ de uma grande construtora não é o mesmo montante que os $2 \%$ de um empresa de médio ou pequeno porte, gerando, por si só, uma diferença abismal entre a permissão legal de contribuir com doações. O mesmo raciocínio pode ser aplicado pode ser aplicado às pessoas físicas e o limite de $10 \%$.

Faz-se muito necessária a existência de limites de doaçôes. Contudo, cabe ressaltar que limites nominais muito ajustados e desconexos da realidade também carecerão de efetividade,

49. SCARROW, Susan E. "Explaining Political Finance Reforms: Competition and Context”. In: Party Politics. v. 10. $n^{\circ}$ 6. Sage, London, 2004. p. 653-655. Em matéria de financiamento político, é frequente que os partidos não apóiem a atitude de "quanto mais, melhor" (inclusive porque ante de uma reforma não está claro quem será o verdadeiro beneficiário), mas a tendência será sempre a de apoiar o aumento dos ingressos ou de limitar seus beneficiários.

50. FISHER, Justin; EISENSTADT, Todd. A. Op. Cit. p. 623.

51. BALMELLI, Tiziano: Le financement des Partis Politiques et des Campagnes Électorales: Entre Exigences Démocratiques et Corruption. Universitaires Fribourg, Suisse, 2001. p. 24-25.

52. Aqui se faz menção do teor da resolução nº 23.406/2014 do Tribunal Superior Eleitoral, que limita o autofinanciamento a 50\% do patrimônio informado à Receita Federal nas eleições de 2014, regra esta que novamente não atende ao principio da igualdade entre os competidores eleitorais, considerando as expressivas diferenças econômicas entre os candidatos. 
já que o efeito é o mesmo que o das estritas proibições no sistema. Tais regras serão sistematicamente violadas ou ignoradas. ${ }^{53}$

Outro item que colabora muito com a instabilidade do sistema de financiamento é a ausência de um mecanismo de cálculo para o limite máximo de gastos dos partidos e candidatos. Não há como atribuir qualquer tipo de eficácia para o art. 17-A constante na Lei n 9.504/97, uma vez que deixar a critério dos atores políticos os seus próprios limites é sinônimo de não estabelecer limite algum. Essa lacuna contribui diretamente para o encarecimento das campanhas e para a dependência de partidos e candidatos dos recursos econômicos vindos das grandes empresas, embora arbitrar um valor a ser gasto para as campanhas é algo muito difícil, já que não há uma forma de "tabelar" uma campanha moderna e eficaz. Tal ponto é muito mais controvertido do que o limite de doaçóes porque se conecta diretamente com o direito do candidato em se promover, de se fazer conhecer.

Agora bem, o cerne da questão é, definitivamente, a transparência do financiamento de partidos e candidatos, algo que é marginalizado nas discussões sobre o tema. $\mathrm{O}$ financiamento corrupto ainda prevalecerá pela falta ou ineficácia dos mecanismos de controle, tanto pela opacidade quanto pela ocultação de dados. Não obstante, não é suficiente que exista um sistema de controle. Com o desenvolvimento de conceitos como o de accountability, a transparência deve contar com um sistema simplificado e de fácil divulgação, porque introduzir ferramentas que acabam dificultando o acesso aos dados por parte do público é algo muito pouco eficaz frente aos objetivos que se perseguem. ${ }^{54}$ De fato, é perceptível que a maioria dos países de democracia ocidental conta com mecanismos de controle, geralmente fruto de reformas legislativas pouco reflexivas sobre como realizar este controle, como também é o caso do Brasil. Pode-se sustentar que há muitas leis para tão pouco controle. ${ }^{55}$

No caso do controle realizado pelo TSE, cada um dos atores que pode receber doação e assumir despesas no processo eleitoral é obrigado a fazer prestação de contas. Esta prestação de contas assume a forma de uma contabilidade que se denomina de partida dobrada, para que se zere a relação entre receitas e despesas, por um lado, e facilitar a fiscalização do ponto de vista contábil, por outro. É com este objetivo que os dados estão organizados nas planilhas disponibilizadas pelo TSE, e não em função de uma transparência e publicidade que permita aos cidadãos - e até aos órgãos de controle - uma fiscalização eficaz na arrecadação de valores por parte de partidos e candidatos. Uma evidência disto é a inexistência de um identificador único que permita capturar inequivocamente um agente em diferentes planilhas de prestação

53. Cite-se a proposta de lei elaborada pelo Movimento de Combate à Corrupção, Eleições Limpas, que sugere um limite nominal de R \$700,00 por pessoa física. Ainda que torne mais igual as regras de doaçóes privadas, esse valor não terá o condão de resolver o problema ou afastar a incidência de financiamento irregular, uma vez que é um montante quase irrisório. Um valor mais alto - como $\mathrm{R} \$ 5.000,00$ reais - teria mais efetividade e atenderia mais à realidade.

54. VILLORIA MENDIETA, Manuel: La Corrupción Política. Ed. Sintesis, Madrid, 2006. p. 238-239.

55. PINTO-DUSCHINSKY, Michael. Financing Politics: A Global View. In: Journal of Democracy. $\mathrm{n}^{\circ}$ 4, vol. 13, oct. ed. John Hopkins University Press, Washington, 2002. p. 80-81. 
de contas. ${ }^{56}$ Portanto, esta prestação de contas pouco ou nada colabora com a real verificação das operações realizadas durante a campanha eleitoral.

Por isso, o desafio principal dos sistemas democráticos é justamente conciliar a necessidade de financiamento sem que isso facilite a venda de políticas aos doadores. $\mathrm{O}$ financiamento de partidos e de campanhas é uma peça fundamental para determinar a direção da sua conduta. Tal decisão pode influir no resultado das urnas, e não é igual se estas forças políticas recebem periodicamente uma quantidade considerável de contribuiçóes de pequeno valor ou se recebem poucas doações, mas de elevado valor. ${ }^{57}$ Esses aspectos devem ser detalhadamente avaliados no momento da elaboração das regras sobre o financiamento dos partidos. ${ }^{58} \mathrm{~A}$ transparência deve ser a base do sistema, e essa, aliada a um correto e equilibrado sistema de sanções determinará que os mecanismos de controle previstos sejam eficazes. ${ }^{59}$ Se não é assim, qualquer intervenção legislativa no tema pode não ter efeito algum. Os benefícios da "accountability", aliados com a publicidade de dados e eleitores informados, possuem uma eficácia muito maior do que uma legislação restritiva ou proibitiva que acaba, indiretamente, conduzindo todo o sistema para a corrupção. A política brasileira não permite mais que a ingenuidade bloqueie a visão do atual panorama. Moralização sim, porém com alvos corretos.

56. Exemplo é descrito por Horochovski et al: “Um candidato a vereador que, ao receber recursos de um candidato a prefeito, declara o recebimento ora usando o CNPJ da candidatura correspondente, ora o CPF do candidato a prefeito ("doador", neste caso), o que pode sugerir a existência de dois doadores distintos quando, na realidade, se trata de um mesmo agente. Situação semelhante pode ocorrer na relação entre um comitê e um candidato, na qual este, ao declarar receita advinda daquele, cita apenas o nome, frequentemente genérico, de "Comitê Financeiro Único", omitindo a unidade eleitoral e o partido. Como consequência, tome-se a seguinte hipótese: uma doação de $\mathrm{R} \$ 100.000,00$ destinada a um partido, transferida a um comitê e distribuída entre várias candidaturas poderá replicar-se nas diferentes tabelas de receitas dando a impressão da realização de um valor significativamente maior, falseando um cálculo bastante popular chamado "custo do voto". É necessário frisar, também, que partidos e comitês podem arcar diretamente com despesas de candidaturas, parcial ou totalmente. Neste caso, na prestação de contas do candidato, esta despesa não aparece como doação". (In: Horochovski, Rodrigo Rossi; et al. Redes de Financiamento Eleitoral nas Eleições de 2008 no Litoral do Paraná. Paraná Eleitoral, v. 3, n. 1, 2014.p. 105-106).

57. WEBER, Max: Economía y Sociedad I: Teoría de la Organización Social. Ed. Fondo de Cultura Económica, Derechos Fundamentales, México, 1944. p. 301.

58. Para WARE, em um sistema ideal, deveria se atender simultaneamente a três aspectos. O primeiro se refere a fornecer aos partidos os recursos suficientes para que estabeleçam conexões com os votantes. Além disso, deve-se fazer com que a arrecadação de recursos não seja a principal atividade de tais organizações, dando-os ao mesmo tempo certo grau de autonomia em relação com os grupos de interesses. Enfocando tais objetivos, o autor sugere que tenham informes públicos das contribuiçóes para os partidos políticos e candidatos e seus gastos, junto com a proibição de contribuições de determinadas fontes, aquisição de alguns serviços e a limitação de alguns tipos de gastos, completando com medidas de financiamento público. (In: WARE, Alan. "Conclusions. Op. Cit." p. 234-235).

59. BALMELLI, Tiziano: Op Cit. p. 382-385. 


\section{Referências Bibliográficas}

ALBERTO CORDERO, Luis. "La Fiscalización del Financiamiento de los Partidos Políticos: un Asunto de Conciencia Crítica". In: AA.VV:: Administración y Financiamiento de las Elecciones en el Umbral del Siglo XXI - Memoria del III Congreso Internacional de Derecho Electoral. Tomo II, Instituto de Investigaciones Jurídicas, DF, México, 1999. p. 381-403.

ALEXANDER, Herbert. E. "Money and Politics: Rethinking a Conceptual Framework". In: ALEXANDER, H. E. (ed.): Comparative Political Finance in the 1980's. Cambridge University Press, UK, 1989. p. 9-23.

AMARAL, Francisco: Direito Civil - Introdução. $3^{\circ}$ ed., Rio de Janeiro: Renovar, 2000.

ARGANDOÑA, Antonio."La Financiación de los Partidos Políticos y la Corrupción en las Empresas". In: Papeles de Ética, Economía y Dirección. nº 6, [s.1.], 2001.

BALMELLI, Tiziano: Le financement des Partis Politiques et des Campagnes Électorales: Entre Exigences Démocratiques et Corruption. Universitaires Fribourg, Suisse, 2001.

BRITO, Walderes Lima de "Superação da apatia política pela valorização de novas práticas de participação cidadã". Disponível em $<<$ http://www.pucgoias.edu.br/ucg/ser/ArquivosUpload/1/file/Artigos/pdf/superacao_apatia.pdf>> Acesso em 03.04.2014.

BURNELL, Peter."Introduction”. In: BURNELL, P., WARE, A. (eds.): Funding Democratization, Manchester University Press, UK, 1998. p. 1-21.

CASTILLO, Pilar. del."Objetivos para una Reforma de la Legislación sobre Financiación de los Partidos Políticos". In: La Financiación de los Partidos Políticos. Cuadernos y Debates, n 47 , Centro de Estudios Constitucionales, Madrid, 1994. p. 53-64.

CORTÉS BURETA, Pilar: Recursos Públicos y Partidos Políticos: Balances y Perspectivas de Reforma. Centro de Estudios Políticos y Constitucionales, Madrid, 2003.

CUNHA, Camila Santos da; EPPLE, Cristiane; HERATH, Maikiely. O direito fundamental de participação social no estado democrático de direito. Disponível em $<<$ http://www. conpedi.org.br/manaus/arquivos/anais/brasilia/04_365.pdf >> Acesso em 03.04.2014.

DALLARI, Dalmo de Abreu: O que é participação Política?. São Paulo: Brasiliense, 1999.

FERREIRA RUBIO, Delia. "Financiamento de Partidos e Campanhas: Fundos Públicos versus Fundos Privados". In: Novos Estudos, n 73, nov. ed. CEBRAP, 2005. p. 5-15.

GARCÍA VIÑUELA, Enrique. "La Regulación del Dinero Público". In: Revista Española de Investigaciones Sociológicas - REIS, no 118, abr/jun, CIS, Madrid, 2007. p. 65-95. 
GIL CASTELLANO, José. "La Financiación de los Partidos Políticos: El Estado de la Cuestión". In: Cuadernos Constitucionales de la Cátedra Fadrique Furió Ceriol, nº 36/37, Valencia, 2001. p. 249-260.

GONZÁLEZ-VARAS, Santiago: La Financiación de los Partidos Politicos. Dykinson, Madrid, 1995.

GRAZIANO, L. O lobby e o interesse público. Revista Brasileira de Ciências Sociais. v. 12, n 35, fev., 1997. Disponível em: << http://www.scielo.br/scielo.php?script=sci_arttext\&pid $=$ S0102-69091997000300009 $>>$ Acesso em 20.08.2014.

http://www.idea.int/political-finance/question.cfm?field=248\&region=-1

http://www.excelencias.org.br/docs/custo_do_voto.pdf

KELSEN, Hans: Teoria Geral do Direito e do Estado. São Paulo: Martins Fontes, 1995.

LANCHESTER, Fulco. "Introduzione: Il Finanziamento della Politica tra forma de Stato e Vincoli Sistemici". In: LANCHESTER, F. (a cura de): Finanziamento della Politica e Corruzione. Giuffrè, Milano, 2000. p. 1-21.

LEONARDO, Rodrigo Xavier."Revisitando a teoria da pessoa jurídica na obra de J. Lamartine Corrêa de Oliveira”. Disponível em $<<$ http://ojs.c3sl.ufpr.br/ojs/index.php/direito/ article/view/14977>> Acesso em 03.04.2014.

LUCIANI, Massimo. "Danaro, Política e Diritto". In: Rivista di Diritto Costituzionale. Ed. G.Giappichelli, Torino, 2006. p. 3-26.

MARTÍNEZ SOSPEDRA, Manuel. La Financiación de los Partidos Políticos. Ensayo de Aproximación. In: Cuadernos Constitucionales de la Cátedra Fadrique Furió Ceriol, no 11/12, Valencia, 20 época, 1995. p. 5-40.

: Introducción a los Partidos Politicos. Ariel, Barcelona, 1996.

MILYO, Jeffrey. “The Political Economics of Campaign Finance”. In: The Independent Review. v. III. no 4, [s.1.] 1999. p. 537-547.

MOLINA VEGA, José Enrique; SADEK, María Tereza. "Participación Política". In: AA.VV.: Diccionario Electoral. CAPEL-IIDH, Costa Rica, 1989. p. 513-528.

MURAYAMA, Ciro. “Dinero, Medios y Elecciones". In: Revista Nexos, n 331, julio, 2005. $<<$ http://www.nexos.com.mx/articulos.php?id_article $=4298$ id_rubrique $=150>>$ Acesso em: 23,02.2014. 
NASSMACHER, Karl-Heinz. "Comparative Political Finance in Established Democracies". In: NASSMACHER, K-H. (ed.): Foundations for Democracy - Approaches to Comparative Political Finance. ed. Nomos Verlagsgesellschaft, Baden-Baden, 2001. p. 9-33.

. "Introduction: Political Parties, Funding and Democracy". In: AUSTIN, R.; TJERNSTRÖM, M. (eds.): Funding of Political Parties and Election Campaigns. International IDEA, Stockholm, 2003. p. 1-19.

PAJARES MONTOLIO, Emilio: La Financiación de las Elecciones. Congreso de los Diputados, Madrid, 1998.

PINTO-DUSCHINSKY, Michael. Financing Politics: A Global View. In: Journal of Democracy. $\mathrm{n}^{\circ}$ 4, vol. 13, oct. ed. John Hopkins University Press, Washington, 2002. p. 69-86.

RONCERO, Francisco Capilla: La persona jurídica - funciones y disfunciones. Madrid: Tecnos, 1984.

SAMUELS, David. "Money, elections and democracy in Brazil". In: Latin America Politics and Society. v. 43, n. 2, 2001, p. 27-48.

: Ambition, federalism and legislative politics in Brazil, UK: Cambridge University Press, 2003.

"Financiamento de campanhas no Brasil e propostas de reforma". In: SOARES, Gláucio Ary D.; RENNÓ, Lúcio R. (orgs.): Reforma Política - Lições da Historia Recente. Rio de Janeiro, FGV, 2006. p. 133-153.

SANTANO, A. C. A proibição das pessoas jurídicas em doar recursos econômicos para as campanhas eleitorais brasileiras: certo ou errado?. In: SANTANO, A. C.; SALGADO, E. D. Direito Eleitoral - debates ibero-americanos. Memórias do V Congresso Ibero-americano de Direito Eleitoral e do IV Congresso de Ciência Política e Direito Eleitoral do Piauí. Curitiba: Íthala, 2014. p. 363-382.

SATRUSTEGUi GIL DELGADO, Miguel. "La Reforma Legal de los Partidos Políticos". In: Revista Española de Derecho Constitucional. año 16, nº 46, ene/abr., 1996. p. 81-105.

SCARROW, Susan E. "Explaining Political Finance Reforms: Competition and Context". In: Party Politics. v. 10. nº 6. Sage, London, 2004. p. 653-675.

VERBA, Sidney; NIE, Norman. H.; KIM, Jae On: The modes of democratic participation: a cross-national comparison. Sage: Beverly Hills, California, 1971.

; NIE, Norman H.: Participation in America - Political Democracy and Social Equality. Harper \& Row Publishers: New York, 1972. 
; SCHLOZMAN, Kay Lehman; BRADY, Henry E.: Voice and equality. Civic voluntarism in American politics. Cambridge, Mass.: Harvard University Press, 1995.

VILLORIA MENDIETA, Manuel: La Corrupción Política. Ed. Sintesis, Madrid, 2006.

WARE, Alan. "Conclusions". In: BURNELL, P., WARE, A. (eds.): Funding Democratization, Manchester University Press, UK, 1998. p. 229-243.

WEBER, M.: Economía y Sociedad I: Teoría de la Organización Social. Ed. Fondo de Cultura Económica, Derechos Fundamentales, México, 1944.

www.asclaras,org.br

www.tse.jus.br

ZOVATTO, Daniel: Dinero y Política en América Latina: Una Visión Comparada. International IDEA, Lima, 2003.

; FREIDENBERG, Flavia. "Democratización Interna y Financiamiento de los Partidos Políticos”. In: PAYNE, M.; et al (eds.): La Política Importa: Democracia y Desarrollo en América Latina. BID e Instituto Internacional para la Democracia y la Asistencia Electoral, Washington D.C., 2006. p. 197-238. 
Recebido em: 08/04/2015

Aceito em: 25/05/2015

\section{Como citar}

SANTANO, Ana Claudia. Menos proibições e mais transparência: as (falsas) promessas sobre a vedação de doações de pessoas jurídicas no financiamento de campanhas eleitorais. Ballot. Rio de Janeiro: UERJ. Volume 1 Número 1 Junho 2015. pp. 182-181. Disponível em: [http:// www.e-publicacoes.uerj.br/index.php/ballot]

\section{(c) (1)(0)}

A Revista Ballot está licenciada sob uma licença Creative Commons Atribuição - Não Comercial - Compartilha Igual 3.0 Não Adaptada. 